Revista Brasileira de Agricultura Irrigada v.13, nº.4, p. 3568 - 3577, 2019

ISSN 1982-7679 (On-line)

Fortaleza, CE, INOVAGRI - http://www.inovagri.org.br

DOI: $10.7127 /$ rbai.v13n4001084

Protocolo 1084.19 - 13/04/2019 Aprovado em 05/07/2019

\title{
CRESCIMENTO DE MUDAS DE PEPINO SOB RESTRIÇÃO HÍDRICA E DOSES DE ESTERCO BOVINO
}

Francisco Vanies da Silva Sá ${ }^{1 *}$, Evandro Franklin de Mesquita ${ }^{2}$, Francisco Marto de Souza ${ }^{3}$, Daniel da Silva Ferreira ${ }^{4}$, Ana Raquel de Sousa Ferreira ${ }^{4}$, Anailson de Sousa Alves ${ }^{5}$

\section{RESUMO}

A baixa disponibilidade de água e o baixo teor de matéria orgânica no solo, são fatores limitantes à produção agrícola em regiões de clima árido e semiárido. Assim, objetivou-se avaliar diferentes doses de esterco bovino e níveis de água disponível no substrato, para a produção de mudas de pepino. O estudo foi realizado em casa de vegetação, avaliando-se dois níveis de água disponível no substrato (100 e 50\%) e quatro doses de esterco bovino $(0,20,40$ e $60 \%$ do volume do substrato), arranjados em esquema fatorial, 2 x 4, em delineamento experimental de blocos ao acaso, com cinco repetições, sendo que cada repetição foi constituída por três plantas úteis. As plantas da variedade Aopdai foram semeadas em vasos com capacidade de $0,2 \mathrm{dm}^{3}$ e conduzidas durante 20 dias após a semeadura, período no qual foram avaliados, crescimento, acúmulo de fitomassa e o teor relativo de água nos tecidos. Na ausência de restrição hídrica os melhores resultados são observados com percentual de $35 \%$ esterco bovino no substrato de plantio. As mudas de pepino Aopdai podem ser produzidas com $50 \%$ de água disponível, quando o substrato for composto por $20 \%$ de esterco bovino, admitindo-se pequenas perdas.

Palavras-chave: Cucumis sativus, irrigação, água disponível, adubação orgânica.

\section{CUCUMBER SEEDLINGS GROWTH UNDER WATER RESTRICTION AND MANURE OF CATTLE DOSES}

\footnotetext{
${ }^{1}$ Eng. Agrônomo, Doutor em Engenharia Agrícola, Programa Nacional de Pós-Doutorado - CAPES, Universidade Federal Rural do Semi-Árido, Campus Mossoró, Mossoró-RN. E-mail: vanies_agronomia@ @otmail.com

${ }^{2}$ Eng. Agrônomo, Doutor em Engenharia Agrícola, Universidade Estadual da Paraíba, Campus IV, Catolé do Rocha-PB. E-mail: elmesquita4@uepb.edu.br

${ }^{3}$ Eng. Agrônomo, Doutorando em Ciência do Solo, Universidade Federal Rural do Pernambuco, Campus Recife, RecifePE. E-mail: francisco.marto@hotmail.com

${ }^{4}$ Licenciados em Ciências Agrárias, Universidade Estadual da Paraíba, Campus IV, Catolé do Rocha-PB. E-mail: danielzsilva3456@gmail.com; Raquel.cat.pb@hotmail.com

5 Licenciados em Ciências Agrárias, Bolsista de Fixação de Doutor, Universidade Estadual do Maranhão, Centro de Estudos Superiores de Balsas, Balsas-MA. E-mail: anailson_agro@hotmail.com
} 


\begin{abstract}
The low water availability and low organic matter content in the soil are limiting factors for agricultural production in arid and semi-arid regions. The objective of this study was to evaluate different doses of bovine manure and available water levels in the substrate for the production of cucumber seedlings. The study was carried out in greenhouse, evaluating two levels of available water in the substrate (100 and 50\%) and four doses of bovine manure (0, 20, 40 and 60\% of the substrate volume), arranged in a $2 \times 4$ factorial scheme, in a randomized block design, with five replicates, each replicate consisted of three useful plants. The plants of the Aopdai variety were sown in pots with a capacity of $0.2 \mathrm{dm}^{3}$ and conducted for 20 days after sowing, during which period, growth, accumulation of phytomass and relative water content in the tissues were evaluated. In the absence of water restriction, the best results are observed with a percentage of $35 \%$ bovine manure in the planting substrate. Aopdai cucumber seedlings can be produced with $50 \%$ water available, when the substrate is composed of $20 \%$ bovine manure, assuming small losses.
\end{abstract}

Keywords: Citrullus lunatus, irrigation, water available, organic fertilization.

\section{INTRODUÇÃO}

O pepino (Cucumis sativus L.) apresenta boa aceitação no mercado consumidor do Nordeste brasileiro, sendo consumido principalmente em saladas. O fato é relacionado a hortaliça se adaptar consideravelmente as condições edafoclimáticas da região, e a capacidade de ser cultivada por pequenos e grandes produtores, com diferentes níveis tecnológicos (AN et al., 2018; BERNARDINI et al., 2018; MEDEIROS et al., 2018; SABÓIA et al., 2018).

Apesar da boa aceitação da cultura, o cultivo agrícola no semiárido é caracterizado por riscos, uma vez que as chuvas são escassas e irregulares, além da baixa disponibilidade de água de qualidade, para que haja adequado suprimento para o pleno crescimento e desenvolvimento das culturas implantadas (ALBUQUERQUE et al., 2016; NÓBREGA et al., 2018). Acrescenta-se isso ao fato do aumento populacional vertiginoso, fazendo necessário a busca por uma agricultura que faça uso mais eficiente dos seus recursos (VIOL et al., 2017).

Como forma de produzir mudas de qualidade, que tolere as intempéries quando forem transplantas para o lugar definitivo, é pertinente o uso de substrato que propicie boa aeração, retenção de água e fornecimento de nutrientes, como atestam Costa et al. (2015), que produziram mudas mais vigorosas com o uso de resíduos agrícolas. O uso de esterco bovino melhora significativamente as propriedades químicas, físicas e biologias do solo, além de ser sustentável e reduzir a necessidade da aplicação de adubos sintéticos (YANG et al., 2016; NASCIMENTO et al., 2017).

Diante da necessidade de realizar uma agricultura mais eficiente, buscando minimizar a demanda por água e fertilizantes o trabalho tem por objetivo avaliar diferentes doses de esterco bovino e níveis de água disponível no substrato, para a produção de mudas de pepino.

\section{MATERIAIS E MÉTODOS}

O estudo foi realizado no período de outubro a novembro de 2015, em casa de vegetação do Centro de Ciências Humanas e Agrárias da Universidade Estadual da Paraíba (CCHA-UEPB), Câmpus IV, Catolé do Rocha, PB, situado a $6^{\circ} 20^{\prime} 38^{\prime \prime}$ de latitude sul, $37^{\circ} 44^{\prime} 48^{\prime \prime}$ de longitude oeste e altitude média de $275 \mathrm{~m}$.

Foram avaliados dois níveis de água disponível no substrato (100 e 50\%) e quatro doses de esterco bovino (0, 20, 40 e $60 \%$ do volume do substrato), arranjados em esquema fatorial, $2 \times 4$, em delineamento experimental de blocos ao acaso, com cinco repetições, 
sendo que cada repetição foi constituída por três plantas.

No preparo do substrato foram coletadas amostras na camada superficial $(0-20 \mathrm{~cm}) \mathrm{de}$ um NEOSSOLO FLÚVICO eutrófico, solos comumente encontrados na região Nordeste, principalmente no estado da Paraíba (EMBRAPA, 2018) e esterco bovino curtido. Para isso, foi realizada a mistura de solo e esterco nas proporções correspondentes aos tratamentos supracitados, e posteriormente a mistura foi acondicionada em vasos polietileno apropriados para produção de mudas, com capacidade de $0,20 \mathrm{dm}^{3}$ do substrato.

Para semeadura utilizou-se a variedade de pepino 'Aopdai' amplamente difundida no Brasil, e principalmente na região Nordeste do país. A semeadura foi realizada colocando-se

$$
\mathrm{Va}=\frac{\mathrm{Mcc}-\mathrm{Ma}}{\mathrm{n}},
$$

três sementes por recipiente. O desbaste das mudas foi feito aos oito dias após a semeadura (DAS), quando as mudas estavam com par de folhas definitivas, deixando a mais vigorosa por recipiente.

A irrigação foi realizada com um volume uniforme de água às plantas, em função da evapotranspiração média no tratamento testemunha, obtida por pesagem. O volume aplicado $(\mathrm{Va})$ por recipiente foi obtido pela diferença entre a média da massa dos recipientes em condição de máxima retenção de água $\left(\mathrm{M}_{\mathrm{cc}}\right)$ e o massa média dos recipientes na condição atual $\left(\mathrm{M}_{\mathrm{a}}\right)$, dividido pelo número de recipientes (n), como indicado na equação 1. $\mathrm{O} \mathbf{M}_{\mathrm{cc}}$ foi determinado saturando-se os recipientes com água e submetendo-os à drenagem até obtenção de massa constante.

A caracterização físico-química do solo (Tabela 1), caracterização química do esterco (Tabela 2) e caracterização química da água de irrigação (Tabela 3) foram realizadas no Laboratório de Irrigação e Salinidade (LIS) do Centro de Tecnologia e Recursos Naturais da Universidade Federal de Campina Grande (UFCG). As amostras de solo e esterco bovino curtido passaram pelos procedimentos de secagem, peneiramento e caracterização física e química seguindo a metodologia proposta pela EMBRAPA (2011). Para análise de água foi adotada a metodologia proposta por Richards (1954). A água da região Semiárida apresenta salinidade variável, e em muitos casos podem afetar o crescimento das plantas, entretanto a água utilizada na irrigação apresentou condutividade elétrica de $0,80 \mathrm{dS}$ $\mathrm{m}^{-1}$, sendo considerada apropriada para a irrigação do pepineiro (ALBUQUERQUE et al., 2016). 
Sá et al.

Tabela 1. Características físicas e químicas do Neossolo Flúvico utilizado na formulação do substrato para produção de mudas de pepino.

\begin{tabular}{cccc}
\hline Características Químicas $($ Fertilidade $)$ & Valor & Características Físicas & Valor \\
\hline Cálcio $\left(\mathrm{cmol}_{\mathrm{c}} \mathrm{dm}^{-3}\right)$ & 2,34 & Areia $\left(\mathrm{g} \mathrm{kg}^{-1}\right)$ & 640,00 \\
Magnésio $\left(\mathrm{cmol}_{\mathrm{c}} \mathrm{dm}^{-3}\right)$ & 2,41 & Silte $\left(\mathrm{g} \mathrm{kg}^{-1}\right)$ & 206,00 \\
Sódio $\left(\mathrm{cmol}_{\mathrm{c}} \mathrm{dm}^{-3}\right)$ & 0,02 & Argila $\left(\mathrm{g} \mathrm{kg}^{-1}\right)$ & 154,00 \\
Potássio $\left(\mathrm{cmol}_{\mathrm{c}} \mathrm{dm}^{-3}\right)$ & 0,33 & Classificação textural & Franco \\
Soma de bases $(\mathrm{S})\left(\mathrm{cmol}_{\mathrm{c}} \mathrm{dm}^{-3}\right)$ & 5,10 & Densidade global $\left(\mathrm{g} \mathrm{dm}^{-3}\right)$ & 1,54 \\
Hidrogênio $\left(\mathrm{cmol}_{\mathrm{c}} \mathrm{dm}^{-3}\right)$ & 0,69 & Densidade das partículas $(\mathrm{g}$ & 2,68 \\
Alumínio $\left(\mathrm{cmol}_{\mathrm{c}} \mathrm{dm}^{-3}\right)$ & 0,00 & $\left.\mathrm{dm}^{-3}\right)$ & 42,54 \\
Capacidade de troca de cátions $\left(\mathrm{cmol}_{\mathrm{c}} \mathrm{dm}^{-}\right.$ & 5,79 & Capacidade de campo $\left(\mathrm{g} \mathrm{kg}^{-1}\right)$ & 146,9 \\
Saturação por Bases $(\mathrm{V} \%)$ & 88,00 & Ponto de murcha Permanent $(\mathrm{g}$ & 76,60 \\
Carbonato de cálcio qualitativo & Ausente & Água disponível $\left(\mathrm{g} \mathrm{kg}^{-1}\right)$ & 70,3 \\
Carbono orgânico $(\%)$ & 0,47 & & \\
Matéria orgânica $(\%)$ & 0,81 & & \\
Nitrogênio $(\%)$ & 0,04 & & \\
Fósforo assimilável $(\mathrm{mg} \mathrm{dm})$ & 18,30 & & \\
pH $\mathrm{H}_{2} \mathrm{O}(1: 2,5)$ & 6,00 & & \\
\hline
\end{tabular}

Análises realizadas no Laboratório de Irrigação e Salinidade (LIS/DEAg/CTRN/UFCG), Campina Grande-PB.

Tabela 2. Características químicas do esterco bovino, utilizado na formulação do substrato para produção de mudas de pepino.

\begin{tabular}{ccccccccc}
\hline \multirow{3}{*}{ Esterco bovino } & $\mathrm{pH}$ & $\mathrm{P}$ & $\mathrm{K}$ & $\mathrm{Ca}$ & $\mathrm{Mg}$ & $\mathrm{Na}$ & $\mathrm{Al}$ & $\mathrm{H}$ \\
\cline { 2 - 7 } & $\mathrm{H}_{2} \mathrm{O}$ & $\mathrm{mg} \mathrm{dm}^{-3}$ & $------\mathrm{c}^{-3}$ & 7,7 & 15,9 & 9,18 & 0,00 & 0,00 \\
& 7,75 & 56 & 0,06 & 7,7
\end{tabular}

Análises realizadas no Laboratório de Irrigação e Salinidade (LIS/DEAg/CTRN/UFCG), Campina Grande-PB.

Tabela 3. Características químicas da água utilizada na irrigação de mudas de pepino em ambiente protegido em Catolé do Rocha, PB no período de outubro a novembro de 2015.

\begin{tabular}{|c|c|c|c|c|c|c|c|c|c|c|}
\hline $\mathrm{pH}$ & $\mathrm{CE}_{25^{\circ} \mathrm{C}}$ & $\mathrm{Ca}^{+2}$ & $\mathrm{Mg}^{+2}$ & $\mathrm{Na}^{+1}$ & $\mathrm{~K}^{+1}$ & $\mathrm{Cl}^{-1}$ & $\mathrm{CO}_{3}{ }^{2-}$ & $\mathrm{HCO}_{3}$ & $\mathrm{SO}_{4}^{2-}$ & RAS \\
\hline & $\mathrm{dS} \mathrm{m}^{-1}$ & & & & & ${ }_{c} L^{-1} \ldots$ & & & & $\mathrm{nol}_{\mathrm{c}} \mathrm{L}^{-}$ \\
\hline 7,53 & 0,80 & 2,30 & 1,56 & 4,00 & 0,02 & 3,90 & 0,57 & 3,85 & 0,00 & 2,88 \\
\hline
\end{tabular}

Análises realizadas no Laboratório de Irrigação e Salinidade (LIS/DEAg/CTRN/UFCG), Campina Grande-PB.

Aos 20 dias após a semeadura (DAS), no final do experimento as planas de pepineiro foram avaliadas quanto à altura da planta (AP): obtida do colo à base da folha mais jovem com régua graduada em centímetro; contagem das folhas (NF): foram consideradas as que apresentavam comprimento mínimo de $1,50 \mathrm{~cm}$ e diâmetro do caule (DC): foi determinado com um paquímetro, com as leituras sendo efetuadas a $1,00 \mathrm{~cm}$ de altura na região do colo de cada planta, nos mesmos períodos estabelecidos para mensuração da AP e NF. Posteriormente as análises de crescimento, o material vegetal colhido foi separado em raízes, caules, folhas, e pesados, obtendo-se assim o peso fresco das plantas. Após essa determinação, o material foi acondicionado em sacos de papel e seco em estufa de circulação de ar a temperatura de $60^{\circ} \mathrm{C}$ até atingir peso constante e posteriormente pesado. De posse desses dados obteve a massa seca da raiz (MSR), massa seca da parte aérea (Folhas + Caule) (MSPA). A obtenção da massa seca total (MST) foi 
obtida pela soma das massas de cada uma dessas partes.

$\mathrm{O}$ teor relativo de água nos tecidos (TRA) foi determinado essencialmente, em comparar o teor de água do tecido da planta

$$
\mathrm{TRA}=\frac{\mathrm{MF}-\mathrm{MS}}{\mathrm{MF}} \times 100,
$$

Os dados foram submetidos aos testes de normalidade (SHAPIRO; WILK, 1965) e homogeneidade pelo teste de Bartlett's. Confirmadas as pressuposições da análise de variância (ANOVA), os dados foram submetidos à ANOVA pelo teste $\mathrm{F}$, ao nível de significância de 5\%. Com base na significância dos dados procedeu a análise de regressão para os dados quantitativos, e o teste de Tukey, a 5\% de significância, para os fatores qualitativos, utilizando o software SISVAR (FERREIRA, 2011).

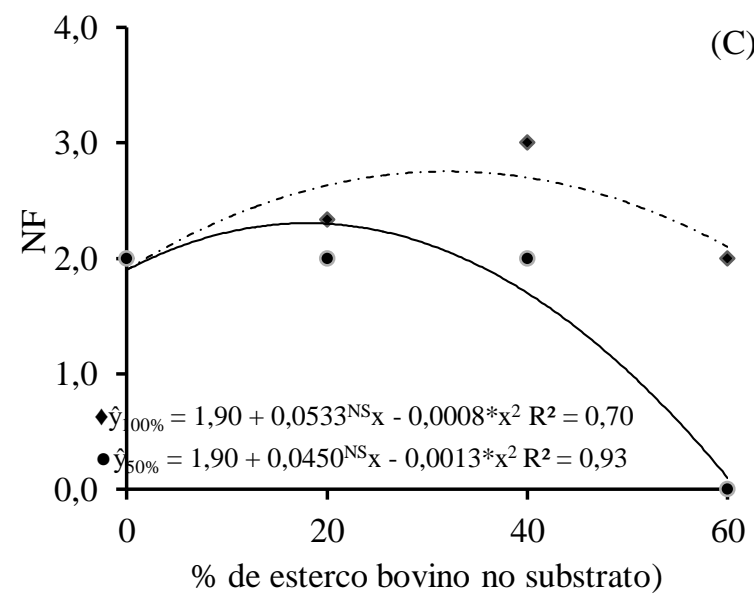

recém-colhida (Massa Fresca $=\mathrm{MF}$ ), com o teor de água do mesmo tecido quando Seco (Massa Seca $=$ MS), expressando-se o resultado numa base percentual (equação 2).

\section{RESULTADOS E DISCUSSÃO}

Houve interação significativa $(p>0,05)$ entre as doses de esterco bovino e os níveis de água disponível no substrato para as variáveis: altura de planta (AP), diâmetro do caule (DC), número de folhas (NF) e teor relativo de água (TRA), massa seca da parte aérea (MSPA), raiz (MSR) e total (MST) das mudas de pepino (Figuras 1A, 1B, 1C e 1D). Esses resultados indicam que a disponibilidade de água no substrato exerce influência direta sobre resposta das mudas de pepino a adubação orgânica com esterco bovino.

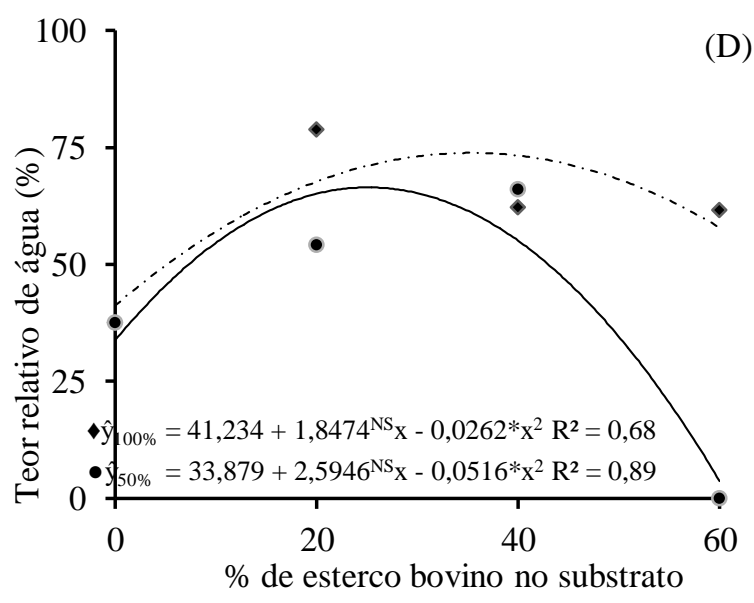

Figura 1. Altura de planta, AP (A), diâmetro do caule, DC (B) e número de folhas, NF (C), Teor relativo de água, TRA (D) de mudas de pepino submetidas a diferentes doses de esterco bovino e níveis de água disponível no substrato $(\bullet 100 \%$ e $\bullet 50 \%$ da AD) aos 20 dias após a semeadura. ** e * $=$ significativo a 1 e $5 \%(\mathrm{p}<0,01$ e $\mathrm{p}<0,05)$ de probabilidade; NS = não significativo.

Nas variáveis AP, DC e NF das mudas de pepino houve comportamento quadrático em função do aumento das doses de esterco bovino, nas duas condições de disponibilidade hídrica do substrato (Figuras 1A, 1B e 1C). Os maiores índices de crescimento das mudas de pepino, quando cultivadas com $100 \%$ de água disponível no substrato foram obtidas com a dose de 30,50, 28,77 e 33,31\% de esterco bovino no substrato, constatando-se valores médios de 4,93 cm, 4,62 $\mathrm{mm}$ e 2,79 folhas, respectivamente.

A redução do crescimento das mudas de pepino nas maiores doses de esterco bovino superiores a $30 \%$ do volume do recipiente pode estar relacionada à decomposição da matéria orgânica, que é dependente da quantidade de água disponível no meio, para 
ativação da biota do solo (KIEHL, 2002). No substrato com $100 \%$ de água disponível, ocorre maior decomposição da matéria orgânica e liberação de nutrientes, favorecendo o crescimento das plantas de pepino, todavia, a liberação excessiva de nutrientes pode ocasionar a toxicidade pelo excesso de nutrientes e de íons $\mathrm{H}^{+}$no substrato (BERTINO et al., 2015).

Nas mudas de pepino cultivadas com $50 \%$ de água disponível no substrato, os melhores resultados foram obtidos com as doses de 19,54, 22,95 e 17,31\%de esterco bovino no substrato, constatando-se valores médios de 4,19 cm, 4,09 $\mathrm{mm}$ e 2,29 folhas, respectivamente (Figuras 1A, 1B e 1C).

A redução de $100 \%$ para $50 \%$ da água disponível no substrato promoveu pequenas reduções no crescimento, quando se compara os picos de máximos crescimento, sendo averiguadas reduções de 15,01; 11,47 e $17,92 \%$ nas variáveis AP, DC e NF, respectivamente (Figuras 1A, 1B e 1C). Porém, com o aumento das doses de esterco bovino no substrato acima dos picos de máximo citados para AP, DC e NF, promoveu reduções no crescimento das muda de pepino mais acentuadas, principalmente no tratamento com 50\% água disponível no substrato, ocasionado a morte de todas as plantas na maior dose de esterco bovino estudado (60\%) (Figuras 1A, 1B e 1C).

Em estudo realizado com mudas de melancia, Sá et al. (2017) constataram em condições de disponibilidade adequada de água, reposta linear do crescimento das mudas em função do incremento das doses de esterco bovino no substrato. Os autores op cit. observaram que em condições de estrese hídrico, as doses de esterco bovino acima de $20 \%$ do volume do substrato intensificaram o efeito do estresse hídrico sobre as mudas. Quando a disponibilidade de água no substrato é baixa, ocorre aumento na concentração de sais provenientes da decomposição esterco, reduzindo ainda mais o potencial hídrico do substrato, em função da redução do potencial osmótico, afetando absorção de água e nutrientes, e consequentemente o crescimento das mudas (ALBUQUERQUE et al., 2016; SÁ et al., 2015, 2017).

A água é um fator crucial para a produção agrícola, de modo que sua falta ou excesso afetam o rendimento das culturas significativamente, tornando-se necessário o manejo racional para maximizar a produção das culturas (MORAIS et al., 2008). A irrigação para o cultivo em recipiente (vasos), quando comparada aos cultivos em campo, apresentam maiores riscos de estresse hídrico, devido as elevadas necessidades instantâneas de água por massa radicular (MELO JÚNIOR et al., 2015).

No teor relativo de água das mudas de pepino houve comportamento quadrático em função das doses de esterco bovino no substrato, para duas condições de disponibilidade de água no substrato. Os maiores teores relativos de água foram verificados sob as doses de esterco de 35,26 e $25,14 \%(\mathrm{v} / \mathrm{v})$, correspondentes aos TRA's de 73,80 e $66,50 \%$, nas mudas cultivadas com 100 e $50 \%$ de disponibilidade de água no substrato, respectivamente (Figura 1D).

As plantas sob condições de restrição de água no substrato $(50 \%$ da $\mathrm{AD})$ obtiveram TRA's semelhantes ao das plantas cultivada sem restrição hídrica ( $100 \%$ da $\mathrm{AD})$, quando receberam doses de esterco bovino adequadas. Assim, pode-se dizem que a matéria orgânica atua positivamente na atenuação do estresse hídrico em mudas de pepino, uma vez que, o estresse hídrico reduz o potencial hídrico do solo, e em consequência gera um gradiente de potencial que afeta absorção de água pelas plantas (GUIMARÃES et al., 2011). Todavia, com a dose adequada de matéria orgânicas $(25 \%)$, as mudas de pepino conseguiram manter o seu potencial de turgor, mesmo em condições de baixa disponibilidade de água no substrato.

Houve interação significativa $(p>0,05)$ entre as doses de esterco bovino e os níveis de água disponível no substrato para as variáveis massa seca da parte aérea (MSPA), raiz (MSR) e total (MST) das mudas de pepino (Figuras 2A, 2B e 2C). Esses resultados indicam que a disponibilidade de água no substrato exerce influência direta sobre o 
acúmulo de biomassa das mudas de pepino em resposta a adubação orgânica com esterco

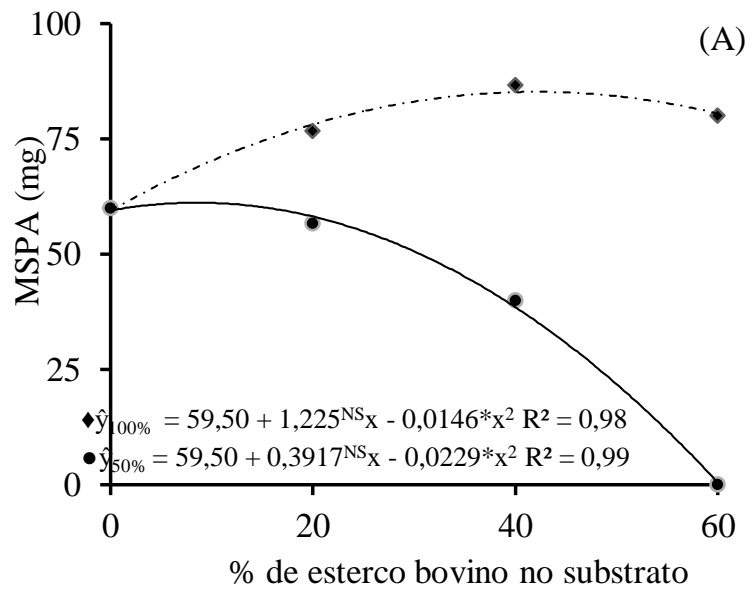

bovino.

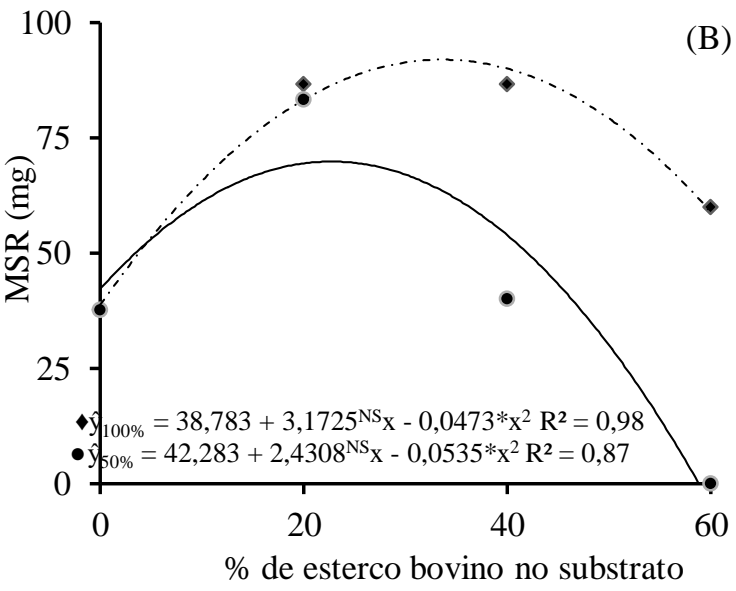

(C)

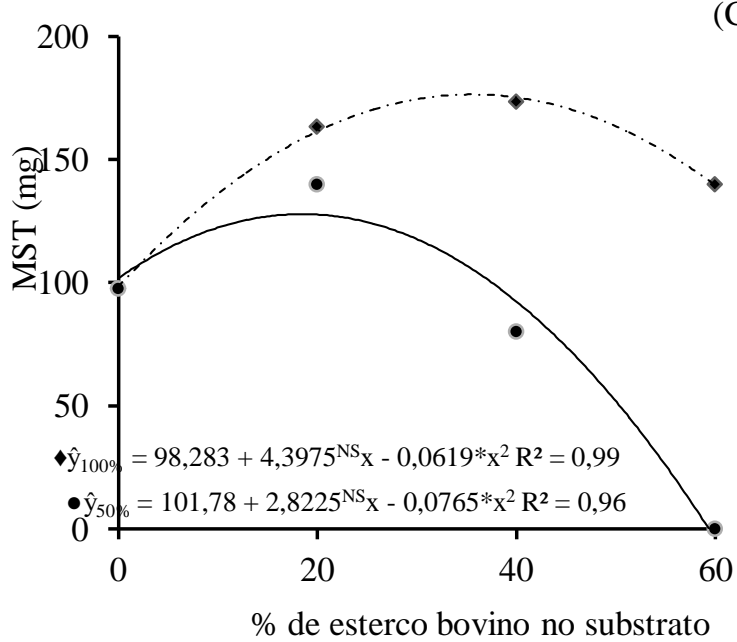

Figura 2. Massa seca da parte aérea, MSPA (A), raiz, MSR (B) e total, MST (C) de mudas de pepino sometidas a diferentes doses de esterco bovino e níveis de água disponível no substrato $(\diamond 100 \% \mathrm{e}$ $\bullet 50 \%$ da AD) aos 20 dias após a semeadura. ** e * = significativo a 1 e $5 \%(\mathrm{p}<0,01$ e $\mathrm{p}<0,05)$ de probabilidade; ${ }^{\mathrm{NS}}=$ não significativo.

Nas variáveis MSPA, MSR e MST das mudas de pepino foi constatado comportamento quadrático em função do aumento das doses de esterco bovino, independente da disponibilidade hídrica do substrato (Figuras 2A, 2B e 2C). Os maiores acúmulos de biomassa ocorreram nas doses de $100 \%$ de água disponível no substrato, nas doses de 42, 34 e 36\% de esterco bovino no substrato, constatando-se valores médios de 85, 92 e $176 \mathrm{mg}$ de MSPA, MSR e MST, respectivamente. Para as mudas de pepino sob $50 \%$ de água disponível no substrato, os maiores resultados ocorreram nas doses de 8,$55 ; 22,72$ e $18,45 \%$ de esterco bovino no substrato, constatando-se valores médios de 61,17; 69,89 e 127,81 mg, respectivamente.

Nas plantas de maneira geral, aproximadamente 80 a $95 \%$ da matéria fresca é composta de água (TAIZ et al., 2015). Em condições de estresse hídrico ocorre a perda progressiva da turgescência protoplasmática, e o aumento da concentração de solutos na planta, promovendo déficits funcionais e danos as estruturas protoplasmáticas (LARCHER, 2006). Entretanto, as mudas irrigadas com $50 \%$ de $\mathrm{AD}$ não diferiram quanto ao crescimento e acúmulo de biomassa das mudas irrigadas com $100 \%$ de $\mathrm{AD}$, na ausência de esterco bovino, indicando que a 
irrigação com $50 \%$ de $\mathrm{AD}$ na fase de mudas não ocasiona déficit hídrico no pepino $\mathrm{cv}$ Aopdai.

As doses mais elevadas de esterco reduziram o acúmulo de biomassa das mudas de pepino nos dois níveis de disponibilidade de água no substrato, sendo os resultados mais drásticos no solo com $50 \%$ de água disponível, averiguado reduções de 28,20, 24,01 e 27, $54 \%$ na MSPA, MSR e MST, respectivamente, quando cultivadas sob a menor disponibilidade de água no substrato (50\% da AD) em relação cultivada sem restrição hídrica $(100 \%$ da $\mathrm{AD})$ (Figuras 2A, $2 \mathrm{~B}$ e $2 \mathrm{C}$ ).

A decomposição da matéria orgânica reduz o pH do substrato, devido a produção de substâncias húmicas, liberação de ácidos orgânicos e liberação de íons $\mathrm{H}^{+}$no substrato (DECARLOS NETO et al., 2002; BERTINO et al., 2015). Assim, é provável que a redução do acúmulo de biomassa das plantas nas maiores doses de esterco bovino esteja relacionada a redução do $\mathrm{pH}$ do substrato. $\mathrm{E}$ que pior desempenho das plantas com menor no solo com $50 \%$ de água disponível, esteja relacionado a maior concentração de íons $\mathrm{H}^{+}$, e consequentemente menor $\mathrm{pH}$, devido ao menor volume de água no solo.

As plantas cultivadas em ambientes com inadequada disponibilidade hídrica, têm maior dificuldade de permanecerem bem nutridas, pois há menores possibilidades dos nutrientes serem solubilizados e absorvidos pelas mesmas, devido à pouca quantidade de água (SÁ et al., 2017). No entanto, as mudas de pepino produzidas com $50 \%$ de $\mathrm{AD}$ quando adubadas com esterco bovino nas doses próximas à $20 \%$ do volume do substrato obtiveram crescimento e acúmulo de biomassa superior as mudas produzidas por Costa et al. (2013) e Medeiros et al. (2018), avaliando substratos alternativos para produção de mudas de pepino. Tais resultados são indicativos que uso de esterco bovino na dose de $20 \%$ do volume do recipiente melhora a performance de mudas de pepino em condições de baixa disponibilidade de água no substrato (Figuras 1 e 2).

\section{CONCLUSÕES}

Os percentuais de esterco bovino na composição do substrato de plantio exercem efeitos diferentes nas mudas de pepino conforme disponibilidade de água no substrato.

$\mathrm{Na}$ ausência de restrição hídrica os melhores resultados são observados com percentual de $35 \%$ esterco bovino no substrato de plantio.

As mudas de pepino Aopdai podem ser produzidas com $50 \%$ de água disponível no substrato, quando o substrato for composto por $20 \%$ de esterco bovino, admitindo-se pequenas perdas.

\section{REFERÊNCIAS BIBLIOGRÁFICAS}

ALBUQUERQUE, J. R. T.; SÁ, F. V. S.; OLIVEIRA, F. A.; PAIVA, E. P.; ARAÚJO, E. B. G.; SOLTO, L. S. Crescimento inicial e tolerância de cultivares de pepino sob estresse salino. Revista Brasileira de Agricultura Irrigada, v. 10, n. 2, p. 486-495, 2016. http://dx.doi.org/10.7127/RBAI.V10N200355

AN, YA-HONG.; ZHOU, H.; YUAN1, Y.; LI, L.; SUN, J.; SHU, S.; GUO, S. 24Epibrassinolide-induced alterations in the root cell walls of Cucumis sativus $\mathrm{L}$. under $\mathrm{Ca}\left(\mathrm{NO}_{3}\right)_{2}$ stress. Protoplasma, v. 255, n. 3, p. 841-850, 2018. http://dx.doi.org/10.1007/s00709-017-1187-8

$\begin{array}{llrr}\text { BERNARDINI, } & \text { C.; } & \text { ZANNONI, } & \text { A.; } \\ \text { BERTOCCHI, } & \text { M.; } & \text { TUBON, } & \text { I.; }\end{array}$ FERNANDEZ, M.; FONI, M. Water/ethanol extract of Cucumis sativus L. fruit attenuates lipopolysaccharide-induced inflammatory response in endothelial cells. BMC Complementary and Alternative Medicine, v. 18, paper 194, p. 1-9, 2018. http://dx.doi.org/10.1186/s12906-018-2254-1

BERTINO, A. M. P.; SÁ, F. V. S.; MESQUITA, E. F.; PAIVA, E. P.; ARAÚJO, E. B. G.; SOUTO, L. S. Emergência e crescimento inicial de plântulas de maracujazeiro amarelo sob doses de esterco 
caprino no substrato. Acta Iguazu, v. 4, n. 2, p. 1-12, 2015

COSTA, E.; SANTO, T. L. E.; SILVA, A. P.; SILVA, L. E.; OLIVEIRA, L. C.; BENETT, C. G. S.; BENETT, K. S. S. Ambientes e substratos na formação de mudas e produção de frutos de cultivares de tomate cereja. Horticultura Brasileira, v. 33, n. 1, p. 110118, 2015. http://dx.doi.org/10.1590/S0102053620150000100018

COSTA, L. A. M.; COSTA, M. S. S. M.; PEREIRA, D. C.; BERNARDI, F. H.; MACCARI, S. Avaliação de substratos para a produção de mudas de tomate e pepino. Revista Ceres, v. 60, n. 5, p. 675-682, 2013. http://dx.doi.org/10.1590/S0034737X2013000 500011

DECARLOS NETO, A.; SIQUEIRA, D. L.; PERREIRA, P. R. G.; ALVAREZ, V. H. Crescimento de porta-enxertos de citros em tubetes influenciados por doses de N. Revista Brasileira de Fruticultura, v. 24, n. 1, p. 199-203, 2002. http://dx.doi.org/10.1590/S0100-

29452002000100043

EMBRAPA. Centro Nacional de Pesquisa de Solos. Manual de métodos de análise do solo. 3 ed. Rio de Janeiro, 2011, 230 p. (Embrapa - CNPS. Documentos, 132).

EMBRAPA. Centro Nacional e Pesquisa de Solos. Sistema Brasileiro de Classificação de Solos. 5. ed. Brasília, DF: Embrapa Solos 2018. 356p.

FERREIRA, D. F. Sisvar: a computer statistical analysis system. Ciência e Agrotecnologia, v. 35, n. 6, p. 1039-1042, 2011.

http://dx.doi.org/10.1590/S141370542011000 600001

GUIMARÃES, C. M.; STONE, L. F.; OLIVEIRA, J. P.; RANGEL, P. H. N.; RODRIGUES, C. A. P. Sistema radicular do arroz de terras altas sob deficiência hídrica. Pesquisa Agropecuária Tropical, v. 41, n. 1, p. 126-134, 2011.

KIEHL, E.J. Manual de Compostagem: Maturação e qualidade do composto. $3^{\text {a }}$ Edição. Piracicaba, SP: E. J. Kiehl, 2002. 171 p.

LARCHER, W. Ecofisiologia vegetal. São Carlos: RIMA Artes e Textos, 2006. 532p.

MEDEIROS, M. B. C. L.; JESUS, H. I.; SANTOS, N. F. A.; MELO, M. R. S.; SOUZA, V. Q.; BORGES, L. S.; GUERREIRO, A. C.; FREITAS, L. S. Índice de qualidade de Dickson e característica morfológica de mudas de pepino, produzidas em diferentes substratos alternativos. Agroecossistemas, v. 10, n. 1, p. 159-173, 2018.

http://dx.doi.org/10.18542/ragros.v10i1.5124

MELO JÚNIOR, J. C. F.; COSTA, D. S.; GERVÁSIO, E. S.; LIMA, A. M. N.; SEDIYAMA, G. C. Efeito de níveis de depleção de água no substrato e doses de fertilizante de liberação controlada na produção de mudas de maracujazeiro amarelo. Irriga, v. 20, n. 2, p. 204-219, 2015. https://doi.org/10.15809/irriga.2015v20n2p20 4

MORAIS, N. B.; BEZERRA, F. M. L.; MEDEIROS, J. F.; CHAVES W. S. P. Resposta de plantas de melancia cultivadas sob diferentes níveis de água e de nitrogênio. Revista Ciência Agronômica, v. 39, n. 3, p. 369-377, 2008.

NASCIMENTO, J. A. M.; SOUTO, J. S.; CAVALCANTE, L. F.; MEDEIROS, S. A. S.; PEREIRA, W. E. Produção de melancia em solo adubado com esterco bovino e potássio. Revista Brasileira de Ciências Agrárias, v. 12 , n. 2, p. 122-127, 2017. http://dx.doi.org/10.5039/agraria.v12i2a5427

NÓBREGA, J. S.; FIGUEIREDO, F. R. A.; NASCIMENTO, R. G. S.; BRUNO, R. L. A.; ALVES, E. U.; E CAVALCANTE, L. F. Qualidade fisiológica de sementes de melão 
pepino sob salinidade crescente da água de irrigação. Revista de Ciências Agrárias, v. 41, n. 4, p. 1011-1018, 2018. http://dx.doi.org/10.19084/RCA18146

RICHARDS, L. A. Diagnosis and improvement of saline and alkali soils. Washington: US Department of Agriculture, 1954. 160p. USDA AgriculturalHandbook, 60.

SÁ, F. V. S.; MESQUITA, E. F.; SOUZA, F. M.; MESQUITA, S. O.; PAIVA, E. P.; SILVA, A. D. Depleção de água e composição do substrato na produção de mudas de melancia. Revista Brasileira de Agricultura Irrigada, v. 11, n. 3, p. 1398-1406, 2017. https://doi.org/10.7127/RBAI.V11N300550

SÁ, F. V. S; BRITO, M. E. B.; FERREIRA, I. B.; ANTÔNIO NETO, P.; SILVA, L. A.; COSTA, F. B. Balanço de sais e crescimento inicial de mudas de pinheira (Annona squamosa L.) sob substratos irrigados com água salina. Irriga, v. 20, n. 3, p. 544-556, 2015. https://doi.org/10.15809/irriga.2015v20n3p54 4

SABÓIA, C. M.; BARBOSA, T. S.; PARENTE, K. M. S.; PARENTE FILHO, E. C. Efeito alelopático de extratos de folhas frescas de Bamburral (Hyptis suaveolens L.) sobre a germinação e o desenvolvimento de plântulas de pepino (Cucumis sativus L.). Revista Fitos, v. 12, n. 1, p. 18-26, 2018. http://dx.doi.org/10.5935/24464775.20180003

SHAPIRO, S. S.; WILK, M. B. An analysis of variance test for normality complete samples. Biometrika, v. 52, n. 3-4, p. 591-611, 1965. https://doi.org/10.1093/biomet/52.3-4.591

TAIZ, L.; ZEIGER, E.; MØLLER, I. M.; MURPHY, A. Plant physiology and development. 6.ed. New York: Sinauer Associates, 2015. 761p.

VIOL, M. A.; CARVALHO, J. A.; LIMA, E. M. C.; REZENDE, F. C.; MATTOS, R. W. P.; RODRIGUES, J. L. M. Déficit hídrico e produção do tomate cultivado em ambiente protegido. Revista Brasileira de Agricultura Irrigada. v. 10, n. 7, p. 1244-1253, 2017. https://doi.org/10.7127/RBAI.V11N100580

YANG R.; MO Y.; LIU C.; WANG Y.; MA J.; ZHANG Y.; LI, H.; ZHANG, X. The effects of cattle manure and garlic rotation on soil under continuous cropping of watermelon (Citrullus lanatus L.). Plos ONE. v. 11, n. 6, p. 1-15, 2016. https://doi.org/10.1371/journal.pone.0156515) 